\title{
Social Skills for Successful Career Development
}

\author{
Dr. Iosif Fragoulis \\ Associate Professor \\ School of Pedagogical and Technological Education \\ Tutor, Hellenic Open University \\ 18 Sokratous Str, Kastelokampos, Rio, 26504, Patra, Greece \\ Tel: 30-2610-910-066 E-mail: sfaka@otenet.gr \\ Dr. Niki Phillips \\ Associate Lecturer/Tutor, Hellenic Open University \\ Head, Human Resource Development, Bank of Cyprus, Greece \\ 151 Dimofontos Str, 11852, Athens, Greece \\ Tel: 30-694-568-1885 E-mail: nphillip@bankofcyprus.gr
}

Received: February 23, 2011 Accepted: March 18, 2011 doi:10.5539/res.v3n1p85

\begin{abstract}
Rapid economic, social and technological changes have turned social skills into an absolute necessity for human resources and the achievement of a successful career. Organizations during employee selection, evaluation or development processes aim mainly in detecting and advancing such skills.

The current paper presents the views of employees working in banking and telecommunications companies in Greece regarding the necessary social skills for achieving a successful career success and professional development. Their views were examined through a small scale empirical research conducted amongst staff and managers of various corporations.

In the conclusion one will find a discussion of the relevant research findings which showed that a high percentage of the research subjects believe that Communication, Leadership, Flexibility and Adaptability skills, are very important for the successful completion of every day professional tasks.
\end{abstract}

Keywords: Skills, Abilities, Social skills, Social-economical-technological changes, Communication, Leadership, Flexibility

\section{DEFINITION OF SOCIAL SKILLS}

Social Skills are not easily defined. One finds the term "Social Skills" with various interpretations and with different contents. However, it is important to initially diversify the term "Skill" from the term "Ability".

According to Cedefop "Ability" refers to the necessary knowledge and experience one has in order to complete a certain task or a particular project. On the other hand a "Skill" is a person's proven capability to exploit his/her know-how, abilities, qualifications or knowledge in order to successfully administer familiar or novel professional situations and requirements (Cedefop, 2002:16). Based on this diversification the term "social skills" is chosen as a more approved term for this research's aims, since the term "ability" only refers to the effective implementation of a particular task.

Perplexity is also detected in the definition of the term "Social". Researching the bibliography, one finds various terms (such as "transferable skills", "basic skills", "emotional skills", "general skills" etc.) all referring to the same set of skills which allow an employee to manage and cope successfully with everyday work requirements (Cedefop, 2002:16).

Goleman classifies Social Skills under the category of Emotional Skills (2000:52). He supports that this category incorporates "empathy", a person's skill associated with the "reading" of others" feelings and the ably handling of their sentiments in general. 
Another interesting explanation of the term "Social Skills" is found in the research "Lifelong learning: citizens" views in close-up» (Chisholm, L., Larson, A., \& Mossoux, A.F., 2004). According to this research "social skills" include the "effective presentation of personal ideas", "problem analysis and solving", "taking initiatives", "planning and organization", "human resources management", "communication and teamwork" and "learning how to learn".

The conceptual explanation given by this research coheres well with the aims and interpretations of this paper.

\section{THE NECESSITY FOR SOCIAL SKILLS}

Contemporary social conditions and changes have been greatly effecting people's lives in many ways and more importantly their professional roles. Such changes focus mainly in three basic levels all of which influence and interact with each other. The most important changes detected during the passing from the industrial production society to the knowledge society are related to social structure, globalization of economy, and radical technological developments (Jarvis, P., 1999. Merriam S., Caffarella, R., 1999. Goleman, D., 2000. Brocket, R., \& Knox, A., 1994).

\subsection{Social Changes}

Demographic changes such as life expectancy increase, (Eurostat, 2002: 7), rising of living standards and reduction of family members numbers (Malthus, 2005), influence society greatly. Hence, population balance changes, the percentage of senior citizens rises and the number of a country's young population decreases.

Transfer of population, economic migration and important work place changes are a few more social phenomena leading to radical changes. A Cedefop report emphasizes that labour market is characterized by strong mobility while the content of professional positions is rapidly altered, due to the introduction of new technologies and the constant changes of organization standards (Cedefop, 2002:10).

\subsection{Economical Changes}

As competition is growing and globalization is being established, the financial field is significantly affected, thus influencing adult's lives and activities. Enterprises aim at cost reduction and product quality and variety increase. Such an aim requires self motivated, creative and ingenious human resources. For successful operations and results achievement, organizations need the input of a great number of employees, all of which must be able to work effectively with each other, find creative solutions and manage critical and difficult situations. Contemporary and competitive enterprises opt to invest in human capital and develop it in various ways. At the same time, European Community emphasizes in human resources, by encouraging and launching relevant investments (Official Journal of the European Union, 2003:10).

\subsection{Technological Changes}

Extensive computer application and electronic data processing in the workplace - both in private and public sectors - require trained staff with good knowledge and skills in information management and new technologies usage. Due to automation of processes work tasks seem easier; however, new abilities are required in order to maintain one's position. Since, new systems are frequently replaced, employees should be prepared to adopt and update their credentials respectively. Logistic, sales and marketing systems are only a few of the production tools functioning on everyday basis within an organization, synthesising and analysing a large amount of work. Likewise, the great and continuous production of knowledge leads to fast depreciation of professional knowledge (IOBE, 1990).

\section{LABOUR MARKET DEMANDS REGARDING SOCIAL SKILLS}

The abovementioned changes in the labor market and society impose new requirements on the work place. Organizations strive to remain competitive through personnel training and development in order to manage and cope with new conditions.

Despite the negative economic environment of the recent years, findings of a research conducted amongst one hundred large and successful organizations worldwide, showed that they invested six billion dollars in activities concerning human resource development. Each one of these organizations offered - on an average - 65 training hours per employee per year (Galvin,2003:18). They select and evaluate their personnel according to new criteria, focusing not on standard qualifications but on abilities such as self management, leadership and effective change management. What they are asking from their employees is not always directly associated with their immediate job tasks or technical knowledge, but with the way they learn and work within a constant changing context.

Regardless the heterogeneity mentioned in the earlier section of this article, in relation to Social Skills definition, there is a common core of certain abilities referred by each on of these definitions. Besides, it is not necessary, or 
always possible, all employees to have the same skills. However some of them are, to some extent, indispensable.

One of the most important Social Skill that seems to be valuable for employees is their ability to communicate effectively. They should be able to express clear and convincing messages and ideas and to actively listen to their co-workers (Goleman, 2000:35-55). Once they have conquered the effective communication skill or have started to appreciate its importance, they must integrate into their professional personality the ability to collaborate with colleagues and work well within the team. That means they should be able to achieve team goals and at the same time nourish and maintain consistency within the team members in order to achieve expected outcomes (Goleman, 2000:35).

Despite the development of communication and teamwork skills, in everyday working life, conflicts, crisis and arguments are part of the agenda. In these cases, it will be useful for employees to have developed their conflict resolution and effective negotiation skills (Goleman, 2000:35). Since crisis and problems are inevitable, it is important for them to know how to confront them, resolve them effectively and even prevent them.

Apart from the above skills, employees should also gradually develop their change management skills, since changes in the work place are a common phenomenon and must be handled and exploited in a creative manner (Goleman, 2000:35). Hence, flexibility and adjustability obtain new dimensions and become more and more valuable skills (Goleman, 2000:32).

Furthermore employees are required to cultivate their desire and ability to lifelong learning and to develop the skill to learn how to learn. This will avance their personalities and will reward them with active citizenship, employment and personal fulfillment.

Planning and organization are also in the necessary social skills list. Employees should be able to prioritize and plan time effectively in order to complete tasks within deadlines and produce high quality and quantity of work.

For team leaders and employees of higher ranking levels management skills are greatly important. Such skills assist them to boost their staff morale in order to complete tasks and achieve goals. Effective managers are expected to practice self awareness, develop their perspective, advance their creativity, delegate tasks, coordinate team members, monitor progress and create a vision for their people (Goleman, 2000:61-63).

None of the above mentioned skills can alone ensure employee effectiveness. Skills are formed in groups. Thus, a successful career path can be followed only when a set of skills is developed, (Goleman, 2000:69).

\section{RESEARCH METHODOLOGY}

\subsection{Research Purpose}

From the literature review regarding development of social skills and/or human resource development methods, one can detect that studies are lacking the investigation of the employees' beliefs in relation to what they consider as important social skills and furthermore the way they would like to be trained so that they can achieve personal and professional development. Current studies seem to mainly focus their explorations towards the organizations' needs and beliefs regarding HR skills, but not the actual HR point of view.

The current study's purpose is to explore social skills from an employee's point of view. More specifically it aims to record and interpret the beliefs of an organization's executive staff regarding the social skills needed for their effective delivery of their job tasks. More specifically their beliefs regarding communication, leadership and flexibility skills will be explored.

\subsection{Research Questions}

1. Are employees' beliefs - regarding the necessity of communication skills in everyday work - relevant to demographic characteristics?

2. Are employees' beliefs - regarding the necessity of leadership skills in everyday work - relevant to demographic characteristics?

3. Are employees' beliefs - regarding the necessity of flexibility skills in everyday work - relevant to demographic characteristics?

\subsection{Research Sample- Limitations}

The research sample consisted of 93 executives employed in Telecommunication and Banking organizations in the regions of Attica and Crete. The research sample was randomly chosen amongst the available executive staff employed by organizations in Athens and Heraklion (Crete). Thus, the research findings can not -and should notbe generalized. 


\subsection{Data Collection}

The questionnaire was chosen as the data collection tool, since it allows the gathering of multitude information in a short period of time. The large number of banking and telecommunication organizations operating in the Attica and Crete Region, combined with the researchers' limited time and availability of transportation, made it difficult to apply any other collection methods (Kvale, 1996:104. Dimitropoulos, 2001: 210. Robson, 2002:271).

\subsection{Data Analysis}

The answers collected by the questionnaire were analyzed by SPSS V. 17, a widely used statistical analysis program in the Social Sciences field.

\section{FINDINGS}

\subsection{Demographic Characteristics}

The research sample's distribution in relation to demographic characteristics is as follows:

\section{Gender:}

57 male members $(61,3 \%)$ and 36 female members $(38,7 \%)$.

Age:

$36(38,7 \%)$ members belong to the age group of $25-34$

$37 \quad(39,8 \%)$ members belong to the age group of 35-44

$18(19,4 \%)$ members belong to the age group of $45-54$

$2 \quad(2,2 \%)$ members belong to to the age group of 55-64

\section{Insert Table 1 about here}

\section{Field-Expertise:}

$63(67,7 \%)$ members are employed in the Banking Field,

$30(32,3 \%)$ are employed in Telecommunications

\section{Years of work experience in the organization:}

37 (39,8\%) members have between 1-10 years of experience,

$38(40,9 \%)$ members have between 11-20 years of experience and

$18(19,4)$ members have between 21-30 years of experience

\section{Professional status:}

$23(27,7 \%)$ members are managers and,

$70(75,3 \%)$ members are general administrative staff

\section{Insert Table 2 about here}

\section{Academic credentials:}

$51(54,8 \%)$ individuals quoted that they have a Finance and Economics Degree, $34(36,6 \%)$ individuals have a Business Administration Degree and $8(8,6 \%)$ quoted that they have a Social Studies or a Humanities Degree.

\section{Post Graduate credentials:}

$36(38,7 \%)$ individuals have a post graduate degree and $57(61,3 \%)$ do not have a post graduate degree.

\subsection{Subjects' beliefs regarding necessary Communication skills}

The single-variable analysis of the subjects' beliefs to the question "How important is expression of personal views with confidence and clarity regarding everyday work activities" showed that:

57 individuals $(61,3 \%)$ answered: Immensely

18 individuals (19,4\%), answered: Considerably

18 individuals (19,4\%) answered: Sufficiently and Remotely

The bivariable analysis of subject answers, using the chi-square criteria, showed statistically important differences $(\alpha<0,05)$, in relation to variables such as gender $(p=0,000)$, age $(p=0,001)$, years of experience $(\mathrm{p}=0,001)$ and professional status $(\mathrm{p}=0,001)$. 


\section{Insert Table 3 about here}

The single-variable analysis of the subjects' beliefs to the question "How important is fluency in written and oral language skills regarding everyday work activities" showed that:

36 individuals $(38,7 \%)$ answered: Immensely

55 individuals $(59,1 \%)$, answered: Considerably

2 individuals (2,2\%) answered: Sufficiently

The bivariable analysis of subject answers, using the chi-square criteria, showed statistically important differences $(\alpha<0,05)$, in relation to variables such as gender $(p=0,000)$, age $(p=0,001)$, years of experience $(\mathrm{p}=0,000)$ and professional status $(\mathrm{p}=0,000)$.

The single-variable analysis of the subjects' beliefs to the question "How important is initiative regarding team projects" showed that:

20 individuals $(21,5 \%)$ answered: Immensely

55 individuals (59,1\%), answered: Considerably

18 individuals $(19,4 \%)$ answered: Sufficiently

The bivariable analysis of subject answers, using the chi-square criteria, showed statistically important differences $(\alpha<0,05)$, in relation to variables such as gender $(p=0,000)$, age $(p=0,002)$, years of experience $(\mathrm{p}=0,000)$ and professional status $(\mathrm{p}=0,000)$.

\section{Insert Table 4 about here}

The single-variable analysis of the subjects' beliefs to the question "How important do you consider active listening and understanding of different views, in everyday work" showed that:

36 individuals $(38,7 \%)$ answered: Immensely

38 individuals (40,9\%), answered: Considerably

19 individuals (20,4\%) answered: Sufficiently

The bivariable analysis of subject answers, using the chi-square criteria, showed statistically important differences $(\alpha<0,05)$, in relation to variables such as gender $(p=0,000)$, age $(p=0,002)$, years of experience $(\mathrm{p}=0,000)$ and professional status $(\mathrm{p}=0,000)$.

The single-variable analysis of the subjects' beliefs to the question "How important do you consider managing conflict in the workplace" showed that:

18 individuals $(19,4 \%)$ answered: Immensely

37 individuals (39,8\%), answered: Considerably

38 individuals (40,8\%) answered: Sufficiently

The bivariable analysis of subject answers, using the chi-square criteria, showed statistically important differences $(\alpha<0,05)$, in relation to variables such as gender $(p=0,000)$, age $(p=0,002)$, years of experience $(\mathrm{p}=0,001)$ and professional status $(\mathrm{p}=0,001)$.

\subsection{Subjects' beliefs regarding necessary Leadership skills}

The single-variable analysis of the subjects' beliefs to the question "How important do you consider taking responsibility regarding your actions and work" showed that:

39 individuals $(41,9 \%)$ answered: Immensely

54 individuals $(58,1 \%)$, answered: Considerably

The bivariable analysis of subject answers, using the chi-square criteria, showed statistically important differences $(\alpha<0,05)$, in relation to variables such as gender $(p=0,000)$, years of experience $(p=0,000)$ and professional status $(\mathrm{p}=0,002)$.

The single-variable analysis of the subjects' beliefs to the question "How important do you consider supporting colleagues regarding completion of their personal tasks" showed that:

18 individuals (19,4\%) answered: Immensely

57 individuals (61,3\%), answered: Considerably 
18 individuals (19,4\%), answered: Sufficiently

The bivariable analysis of subject answers, using the chi-square criteria, showed statistically important differences $(\alpha<0,05)$, in relation to variables such as gender $(\mathrm{p}=0,001)$, years of experience $(\mathrm{p}=0,000)$ and professional status $(\mathrm{p}=0,002)$.

\section{Insert Table 5 about here}

The single-variable analysis of the subjects' beliefs to the question "How important do you consider the ability to create vision for your colleagues" showed that:

36 individuals $(38,7 \%)$ answered: Immensely

38 individuals (40,9\%), answered: Considerably

19 individuals (20,4\%), answered: Sufficiently

The bivariable analysis of subject answers, using the chi-square criteria, showed statistically important differences $(\alpha<0,05)$, in relation to variables such as gender $(\mathrm{p}=0,000)$, years of experience $(\mathrm{p}=0,001)$ and professional status $(\mathrm{p}=0,001)$.

\section{Insert Table 6 about here}

The single-variable analysis of the subjects' beliefs to the question "How important do you consider the ability to impart enthusiasm to your colleagues" showed that:

20 individuals (21,5\%) answered: Immensely

55 individuals (59,1\%), answered: Considerably

18 individuals (19,4\%), answered: Sufficiently

The bivariable analysis of subject answers, using the chi-square criteria, showed statistically important differences $(\alpha<0,05)$, in relation to variables such as gender $(p=0,000)$, years of experience $(p=0,001)$ and professional status $(\mathrm{p}=0,001)$.

\subsection{Subjects' beliefs regarding necessary Flexibility and Adaptability skills}

The single-variable analysis of the subjects' beliefs to the question "How important do you consider the skill of positive reaction and acceptance of new working methods" showed that:

37 individuals $(39,8 \%)$ answered: Immensely

36 individuals (38,7\%), answered: Considerably

20 individuals (21,5\%), answered: Sufficiently

The bivariable analysis of subject answers, using the chi-square criteria, showed statistically important differences $(\alpha<0,05)$, in relation to variables such as gender $(p=0,000)$, years of experience $(p=0,001)$ and professional status $(\mathrm{p}=0,000)$.

\section{Insert Table 7 about here}

The single-variable analysis of the subjects' beliefs to the question "How important do you consider the skill of reconsidering personal views according to new data obtained" showed that:

20 individuals $(21,5 \%)$ answered: Immensely

36 individuals $(38,7 \%)$, answered: Considerably

37 individuals (39,8\%), answered: Sufficiently

The bivariable analysis of subject answers, using the chi-square criteria, showed statistically important differences $(\alpha<0,05)$, in relation to variables such as gender $(p=0,001)$, years of experience $(p=0,000)$ and professional status $(\mathrm{p}=0,001)$.

\section{Insert Table 8 about here}

The single-variable analysis of the subjects' beliefs to the question "How important do you consider the skill of acknowledging the need for constant self development in the work place" showed that:

37 individuals (39,8\%) answered: Immensely

38 individuals (40,9\%), answered: Considerably

18 individuals $(19,4 \%)$, answered: Sufficiently 
The bivariable analysis of subject answers, using the chi-square criteria, showed statistically important differences $(\alpha<0,05)$, in relation to variables such as gender $(p=0,000)$, years of experience $(p=0,002)$ and professional status $(\mathrm{p}=0,000)$.

\section{CONCLUSIONS}

The findings of this research show that a high percentage of the research subjects believe that Communication skills are very important for the successful completion of every day professional tasks. These beliefs are highly influenced by the sample's demographic characteristics such as gender, age, years of experience and professional status. More specifically, females, subjects of younger age, and those with 11 to 20 years of experience, as well as upper level managers, believe that Communication skills influence the successful completion of their everyday duties.

The views expressed by the above mentioned categories are easily understood when one takes into consideration the fact that females are more communicative, while experienced and executive staff have had ample time to recognize the importance of communication skills in their professional careers.

The research also showed that a high percentage of the research subjects believe that Leadership skills are very important for the successful completion of professional duties. These beliefs are highly influenced by the sample's demographic characteristics such as, age, years of experience and professional status. More specifically, middle age subjects, those with 21 to 30 years of experience, as well as upper level managers, believe that Leadership skills influence the successful completion of their everyday duties.

Another set of findings shows that a high percentage of the research subjects believe that Flexibility and Adaptability skills are very important for the successful completion of professional duties. These beliefs are highly influenced by the sample's demographic characteristics such as, age, years of experience and professional status. More specifically, younger age subjects, those with 21 to 30 years of experience, as well as upper level managers, believe that Leadership skills influence the successful completion of their everyday duties.

The views expressed by the above mentioned categories are easily understood when one takes into consideration the fact that younger people are more flexible and adapt well to new conditions, while experienced and executive staff have had ample time to recognize the importance of flexibility skills in their professional careers.

\section{References}

Brocket, R., \& Knox, A. (1994). Experiential Learning, A New Approach. San Francisco: Jossey Bass.

Cedefop. (2002). Training and Learning for skills development: An abstract of Main Points. Luxembourg: Publications Office of European Union.

Chisholm, L., Larson, A., \& Mossoux, A.F. (2004). Lifelong Learning: citizens' views in close-up. Luxembourg: Publications Office of European Union.

Dimitropoulos, E. (2001). Introduction to the Methodology of scientific research. Athens: Ellin. (in Greek)

European Union Newspaper. (2003). Promoting Development of Human Resources and Life Long Learning. 578/EK.

Eurostat Year book. (2002). People in Europe. [Online] Available: http://europa.eu.int/comm/eurostat/public (May, 15,2004)

Galvin, T. (2003). Training Top 100. Training, 40 (12), 18-38.

Goleman, D. (2000). Emotional intelligence in the work place, $7^{\text {th }}$ edition. Athens: Ellinika Grammata. (In Greek).

I.O.B.E. (1990). Technical training needs of the Greek Industry. Athens.

Jarvis, P. (1999). Adult \& Continuing Education, $2^{\text {nd }}$ Ed. London: Routledge.

Kvale, S. (1996). Interviews: An Introduction to Qualitative Research Interviewing. London: Sage Publications.

Malthus, T. (2005). An Essay on the Principle of Population. [Online] Available: http://www.ac.wwu.edu/ $\sim$ stephan/malthus/malthus.0.html (August, 30, 2005).

Merriam S., Caffarella, R. (1999). Learning in Adulthood, a Comprehensive Guide. San Francisco: Jossey Bass.

Official Journal of the European Union. (2003). [Online] Available: http://eur-lex.europa.eu/JOIndex.do?year=2003\&serie $=$ L\&textfield2 $=10 \&$ Submit $=$ Search\&_submit=Search\&ih mlang=en (September 12, 2005). 
Robson, C. (2002). Real World Research. Oxford: Blackwell.

Table 1. Distribution in relation to Age

\begin{tabular}{|l|c|c|}
\hline $25-34$ age group & 36 & $38,7 \%$ \\
\hline $35-44$ age group & 37 & $39,8 \%$ \\
\hline $45-54$ age group & 18 & $19,4 \%$ \\
\hline $55-64$ age group & 2 & $2,2 \%$ \\
\hline TOTAL & $\mathbf{9 3}$ & $\mathbf{1 0 0} \%$ \\
\hline
\end{tabular}

Table 2. Distribution in relation to Professional Status

\begin{tabular}{|l|c|c|}
\hline MANAGERS & 23 & $24,7 \%$ \\
\hline GENERAL ADMINISTRATIVE STAFF & 70 & $75,3 \%$ \\
\hline TOTAL & $\mathbf{9 3}$ & $\mathbf{1 0 0} \%$ \\
\hline
\end{tabular}

Table 3. Skills in relation to Personal views expression

\begin{tabular}{|l|c|c|}
\hline IMMENSELY & 57 & $61,3 \%$ \\
\hline CONSIDERABLY & 18 & $19,4 \%$ \\
\hline SUFFICIENTLY \& REMOTELY & 18 & $19,4 \%$ \\
\hline TOTAL & $\mathbf{9 3}$ & $\mathbf{1 0 0} \%$ \\
\hline
\end{tabular}

Table 4. Initiative in team projects

\begin{tabular}{|l|c|c|}
\hline IMMENSELY & 20 & $21,5 \%$ \\
\hline CONSIDERABLY & 55 & $59,1 \%$ \\
\hline SUFFICIENTLY \& REMOTELY & 18 & $19,4 \%$ \\
\hline TOTAL & $\mathbf{9 3}$ & $\mathbf{1 0 0 \%}$ \\
\hline
\end{tabular}

Table 5. Supporting Colleagues in completing personal tasks

\begin{tabular}{|l|c|c|}
\hline IMMENSELY & 18 & $19,4 \%$ \\
\hline CONSIDERABLY & 57 & $61,3 \%$ \\
\hline SUFFICIENTLY \& REMOTELY & 18 & $19,4 \%$ \\
\hline TOTAL & $\mathbf{9 3}$ & $\mathbf{1 0 0 \%}$ \\
\hline
\end{tabular}

Table 6. Creating Vision for Colleagues

\begin{tabular}{|l|c|c|}
\hline IMMENSELY & 36 & $38,7 \%$ \\
\hline CONSIDERABLY & 38 & $40,9 \%$ \\
\hline SUFFICIENTLY \& REMOTELY & 19 & $20,4 \%$ \\
\hline TOTAL & $\mathbf{9 3}$ & $\mathbf{1 0 0 \%}$ \\
\hline
\end{tabular}


Table 7. Positive reaction and acceptance of new working methods

\begin{tabular}{|l|l|l|}
\hline IMMENSELY & 37 & $39,8 \%$ \\
\hline CONSIDERABLY & 36 & $38,7 \%$ \\
\hline SUFFICIENTLY \& REMOTELY & 20 & $21,5 \%$ \\
\hline TOTAL & $\mathbf{9 3}$ & $\mathbf{1 0 0} \%$ \\
\hline
\end{tabular}

Table 8. Reconsidering personal views

\begin{tabular}{|l|l|l|}
\hline IMMENSELY & 20 & $21,5 \%$ \\
\hline CONSIDERABLY & 36 & $38,7 \%$ \\
\hline SUFFICIENTLY \& REMOTELY & 37 & $39,8 \%$ \\
\hline TOTAL & $\mathbf{9 3}$ & $\mathbf{1 0 0 \%}$ \\
\hline
\end{tabular}

